\title{
Avaliação in vitro da atividade fotoprotetora do extrato hexânico de Psidium araçá (Psidium guineense sw.)
}

In vitro evaluation of photoprotective activity of hexanic extract of Psidium araçá (Psidium guineense sw.) Evaluación in vitro de la actividad fotoprotectiva del extracto hexanico de Psidium araçá (Psidium guineense sw.) Sheyliane Rego MORAIS ${ }^{1}$

Maria Tays Pereira SANTANA ${ }^{1}$ Lucas Linhares GOMES ${ }^{1}$

Thallita Alves dos SANTOS ${ }^{1}$

Yanna Carolina Ferreira TELES ${ }^{2}$

Heloisa Mara Batista Fernandes de OLIVEIRA ${ }^{3}$ Aleson Pereira de SOUSA ${ }^{4}$

Abrahão Alves de OLIVEIRA FILHO ${ }^{1}$

${ }^{1}$ Universidade Federal de Campina Grande (UFCG) Patos - PB, Brasil

${ }^{2}$ Universidade Federal da Paraíba (UFPB) João Pessoa - PB, Brasil

${ }^{3}$ Hospital Universitário Ana Bezerra (HUAB/UFRN) Santa Cruz - RN, Brasil

${ }^{4}$ Doutorando em Desenvolvimento e Inovação Tecnológica de Medicamentos, Universidade Federal da Paraíba (UFPB) João Pessoa - PB, Brasil Resumo

A radiação ultravioleta (UV) é um potente carcinógeno, principalmente a UV-B, capaz de provocar danos ao DNA, relacionado a formação de radiação livres. A excessiva exposição solar e sem prevenção contra os raios UV representa um grande risco para o desenvolvimento de patologias com malignidade, dentre elas o câncer de pele. $O$ emprego de extratos vegetais brasileiros com potencial fotoprotetor é sem dúvida um caminho inovador. O araçá ou araçá-do-campo por exemplo, da família Myrtaceae, espécie Psidium guineense Sw., possui grande potencial para exploração econômica e tem boa aceitação in natura, Dessa forma, o presente estudo tem por objetivo avaliar a atividade fotoprotetora do extrato hexânico do Psidium guineense Sw. Foram realizadas varreduras de 290 a 320nm (com intervalos de $5 \mathrm{~nm}$ ) em concentrações de $50,100,500$ e $1000 \mu \mathrm{g} / \mathrm{mL}$ em amostras de 2,0 mL. Os dados foram aplicados à equação de Mansur para aferir o FPS in vitro. Os resultados dessa pesquisa demonstraram que o extrato hexânico de Psidium guineense Sw. apresenta significativa atividade fotoprotetora nas concentrações de 500 e $1000 \mu \mathrm{g} / \mathrm{mL}$ mostrando-se superior ao FPS necessário. Assim, os resultados sugerem que possa ser utilizado como alternativa fitocosmética, tornando-se uma opção mais acessível.

Descritores: Radiação; Proteção; Neoplasias.

\section{Abstract}

Ultraviolet radiation (UV) is a potent carcinogen, mainly UV-B, capable of causing damage to DNA, related to the formation of free radiation. Excessive sun exposure and without prevention against UV rays represents a great risk for the development of pathologies with malignancy, including skin cancer. The use of Brazilian plant extracts with photoprotective potential is undoubtedly an innovative path. The araçá or araçá-do-campo, for example, of the Myrtaceae family, Psidium guineense Sw., Has great potential for economic exploitation and has good acceptance in natura. Thus, the present study aims to evaluate the photoprotective activity of the hexane extract of Psidium guineense Sw. Scans of 290 to $320 \mathrm{~nm}$ (with $5 \mathrm{~nm}$ intervals) were performed in concentrations of $50,100,500$ and $1000 \mu \mathrm{g} / \mathrm{mL}$ in samples of $2.0 \mathrm{~mL}$. The data were applied to Mansur equation to measure SPF in vitro. The results of this research demonstrated that the hexanic extract of Psidium guineense Sw. Has significant photoprotective activity at concentrations of 500 and $1000 \mu \mathrm{g} / \mathrm{mL}$, showing itself to be superior to the necessary SPF. Thus, the results suggest that it can be used as a phytocosmetic alternative, making it a more accessible option.

Descriptors: Radiation; Protection; Neoplasms.

\section{Resumen}

La radiación ultravioleta (UV) es un potente carcinógeno, principalmente UV-B, capaz de causar daño al ADN, relacionado con la formación de radiación libre. La exposición excesiva al sol y sin prevención contra los rayos UV representa un gran riesgo para el desarrollo de patologías con malignidad, incluido el cáncer de piel. El uso de extractos de plantas brasileñas con potencial fotoprotector es, sin duda, un camino innovador. El araçá o araçá-do-campo, por ejemplo, de la familia Myrtaceae, Psidium guineense Sw., Tiene un gran potencial para la explotación económica y tiene una buena aceptación en la naturaleza. Por lo tanto, el presente estudio tiene como objetivo evaluar la actividad fotoprotectora del hexano de Psidium guineense Sw. Se realizaron exploraciones de 290 a $320 \mathrm{~nm}$ (con intervalos de $5 \mathrm{~nm}$ ) en concentraciones de $50,100,500$ y $1000 \mu \mathrm{g} / \mathrm{ml}$ en muestras de 2,0 ml. Los datos se aplicaron a la ecuación de Mansur para medir SPF in vitro. Los resultados de esta investigación demostraron que el extracto hexánico de Psidium guineense Sw. Tiene una actividad fotoprotectora significativa a concentraciones de 500 y $1000 \mu \mathrm{g} / \mathrm{ml}$, demostrando ser superior al SPF necesario. Por lo tanto, los resultados sugieren que puede usarse como una alternativa fitocosmética, por lo que es una opción más accesible.

Descriptores: Radiación; Protección; Neoplasias.

INTRODUÇÃO

A radiação ultravioleta (UV) é um potente carcinógeno, principalmente a UV-B, capaz de provocar danos ao DNA, relacionado à formação de radiação livres. Após altas doses de raios UV pode-se prejudicar a integridade e morfologia tecidual, provocando uma resposta inflamatória intensa que causa ulceração na epiderme, e uma perda da barreira de proteção ${ }^{1}$.

A excessiva exposição solar e sem prevenção contra os raios UV representa um grande risco para o desenvolvimento de tumores com malignidade. Os filtros solares são uma das formas de proteção da pele. Além disso, o que tem atraído a atenção do mercado é o desenvolvimento dos fotoprotetores obtidos através de formulações e mecanismos de ação inovadores. Ambas as formas de proteger contra radiação, podem hidratar e rejuvenescer a pele ${ }^{2}$.

A utilização de agentes protetores sobre a superfície cutânea integra ainda as ações primárias de prevenção do câncer de pele. A pele do lábio também se torna desprotegida, 
quando exposta, necessitando de agentes que bloqueiem a ação do raios UV, como protetores labiais. Assim, o uso de fotoprotetores é uma providência de baixo custo e efetiva capaz de prevenir até mesmo os casos de melanomas. Dessa forma, o desenvolvimento de formulações mais eficazes e seguras deve ser prioridade no mercado dos cosmecêuticos. $O$ emprego de extratos vegetais brasileiros com potencial fotoprotetor é sem dúvida um caminho para se desenvolverem as competências internas da economia ${ }^{3,4}$.

Os produtos naturais são utilizados pelo ser humano desde os tempos da antiguidade. Possivelmente uma das primeiras formas de utilização tenha sido para alivio e cura de doenças, através da ingestão de ervas e folhas, e atualmente tem crescido como alternativa para prevenção e tratamento de patologias, o que fez aumentar seu uso. Além do fato de $25 \%$ da flora mundial, e da biodiversidade contribuírem para o emprego da fitoterapia no país ${ }^{5,6}$.

Extratos naturais e óleos essenciais por seu potencial fotoprotetor estão sendo utilizados em cosméticos como filtros solares. Mas é necessário para isso, que os mesmos possuam moléculas com estruturas semelhantes às dos filtros químicos sintéticos em sua composição. Por serem misturas de diversas moléculas mais ou menos ativas, não é possível definir a absorção máxima desses produtos. No entanto, podem ser utilizados como potencializadores do FPS $^{7}$.

O araçá (Psidium guineense sw.) compõe a família Myrtaceae, espécie Psidium guineense sw., popularmente conhecido como araçá-comum ou araçá-do-campo. É um fruto que pode ser encontrado em estados de flora silvestre no Brasil, como Pará, Amazonas, Mato Grosso, Minas Gerais, São Paulo, Espírito Santo, Rio de Janeiro e Santa Catarina, além do México, Paraguai e Argentina ${ }^{8}$.

Possui grande potencial para exploração econômica e tem boa aceitação in natura, pois seus frutos além de serem ricos em vitamina $C$, suas raízes são diuréticas e antidiarréticas, e suas cascas têm elevado teor de taninos. Através do fracionamento do extrato bruto com solventes que possuem polaridade crescente, pode-se inferir as possíveis classes de substâncias extraídas nas variadas frações de acordo com suas polaridades. O hexano por exemplo, extrai provavelmente esteroides e terpenos, já compostos como flavonoides, saponinas, taninos, e compostos fenólicos em geral são extraídos pelo acetato de etila ${ }^{9}$.

Dessa forma, o presente estudo tem por objetivo verificar in vitro o potencial fotoprotetor através da determinação do Fator de Proteção Solar FPS do extrato hexânico de Psidium guineense sw.

\section{MATERIAL E MÉTODO}

- Extrato Vegetal

O extrato hexânico de Psidium guineense sw. foi cedido pela equipe da Prof ${ }^{\mathrm{a}}$. Dra. Yanna Teles (UFPB). Inicialmente foi pesado na balança analítica $20 \mathrm{mg}$ do produto natural hexânico, após a pesagem, esse foi solubilizado em $200 \mu \mathrm{L}$ de DMSO (dimetilsulfóxido), em uma gota de Tween 80 e diluído em $2000 \mu \mathrm{L}$ de água destilada. Assim, obteve-se uma solução mãe (solução concentrada) com concentração de $10 \mathrm{mg} / \mathrm{mL}$. - Diluições

Foi feita a diluição da solução concentrada em água destilada nas concentrações de 50, 100, 500 e $1000 \mu \mathrm{g} / \mathrm{mL}$. Para o conhecimento do volume das soluções de estoque utilizou-se a equação de diluição $\mathrm{C} 1 . \mathrm{V} 1$ = C2.V2, de modo que, ao final todas as amostras apresentassem 2,0 mL

- Espectrofotometria na região do ultravioleta

A espectrofotometria de absorção do extrato hexânico de Psidium guineense sw. foi realizada no espectro da radiação ultravioleta como proposto por Mansur e colaboradores ${ }^{10}$ (1986). Assim, foram feitas varreduras de 290 a $320 \mathrm{~nm}$ (em intervalos de $5 \mathrm{~nm}$ ) com duração de 5 minutos, sendo que ao término desse tempo foram efetuadas as mensurações das absorbâncias, como também, a leitura da água destilada (solvente) para regular $0 \%$ de absorbância a cada varredura. Dessa forma, foi utilizado o espectrofotômetro com cubeta de quartzo de $1 \mathrm{~cm}$.

\section{- Cálculo do FPS}

Após a mensuração das absorbâncias, os dados foram aplicados à equação de Mansur et al. $^{10}$ para aferir o FPS in vitro. Essa metodologia relaciona 0 efeito eritemogênico (EE) com a intensidade da radiação (I) conforme o comprimento de onda, metodologia desenvolvida por Sayre et al. ${ }^{11}$. Esses são demonstrados no Quadro 1.

Quadro 1. Relação efeito eritemogênico (EE) versus intensidade da radiação $(I)$ conforme o comprimento de onda $(\lambda)$.

\begin{tabular}{|c|c|}
\hline$\lambda / \mathbf{n m}$ & EE X I \\
\hline 290 & 0,0150 \\
\hline 295 & 0,0817 \\
\hline 300 & 0,2874 \\
\hline 305 & 0,3278 \\
\hline 310 & 0,1864 \\
\hline 315 & 0,0839 \\
\hline 320 & 0,0190 \\
\hline
\end{tabular}

Mansur et al. ${ }^{10}$ também desenvolveram uma fórmula pela leitura de espectrofotométrica da absorbância da solução e fator de correção 
(=10). A equação é observada no Quadro $2, \mathrm{Na}$ qual: $F P S=$ fator de proteção solar; $F C=$ fator de correção, calculado de acordo com dois filtros solares de FPS conhecidos e testados em seres humanos de tal forma que um creme contendo $8 \%$ de homossalato resultasse no FPS 4; $E E(\lambda)=$ efeito eritemogênico da radiação de comprimento de onda; Abs $(\lambda)=a$ absorbância da formulação no comprimento de onda; I $(\lambda)=$ a intensidade da luz solar no comprimento de onda.

Quadro 2. Fórmula de Mansur et al. ${ }^{10}$ para leitura de espectrofotométrica.

FPS espectrofotométrico $=$ FC. ${ }^{320} \Sigma$ EE $(\lambda) . \mathrm{I}(\lambda)$. Abs $(\lambda)$ 290

RESULTADOS E DISCUSSÃO

O produto natural extrato hexânico de Psidium guineense sw. obteve um bom potencial de fotoproteção in vitro nas concentrações equivalentes a $500 \mu \mathrm{g} / \mathrm{mL}$ e $1000 \mu \mathrm{g} / \mathrm{mL}$, com valores de FPS entre 20,77 e 25,01 respectivamente. As menores concentrações do produto equivalente a 50 $\mu \mathrm{g} / \mathrm{mL}$ e $100 \mu \mathrm{g} / \mathrm{mL}$ do extrato hexânico não apresentaram valores consideráveis de fotoproteção, estes estiveram com valor < 6,0 de FPS considerado valor mínimo de captação UV por extratos e soluções avaliados pelo método in vitro, como pode ser visto na Tabela 1.

Tabela 1. Fator de Proteção Solar (FPS) do extrato hexânico de Psidium guineense

\begin{tabular}{l|c|c|c|c}
\hline Concentração & $\mathbf{5 0} \mu \mathrm{g} / \mathbf{m L}$ & $\mathbf{1 0 0} \boldsymbol{\mu g} / \mathbf{m L}$ & $\mathbf{5 0 0} \boldsymbol{\mu g} / \mathbf{m L}$ & $1000 \boldsymbol{\mu g} / \mathbf{m L}$ \\
\hline FPS & 2,698 & 4,843 & 20,77 & 25,01 \\
\multicolumn{5}{l}{ Fonte: Dados da Pesquisa }
\end{tabular}

Segundo Brasil ${ }^{12}$, a RDC No 30 , de $1^{\circ}$ de junho de 2012, da Agência Nacional de Vigilância Sanitária (ANVISA), que aprova 0 regulamento técnico MERCOSUL sobre protetores solares em cosméticos e dá outras deliberações, estabelece que o fator mínimo para proteção solar é 6 (seis).

Analisando os resultados expressos na tabela 1, observa-se que somente as concentrações de 500 e $1000 \mu \mathrm{g} / \mathrm{mL}$ alcançam fator de fotoproteção (FPS) suficiente, sugerindo-o como uma alternativa natural para o mercado de fitocosméticos.

Guaratini et al. ${ }^{13}$, além de Oliveira Junior e Almeida $^{14}$ relatam que pesquisas são realizadas com novas moléculas fotoestáveis para utilização em protetores solares, e atualmente 0 foco tem se voltado para o desenvolvimento de filtros com matérias primas naturais. Associado a isso, os de origem natural apresentam menos efeitos colaterais e menor agressividade ao meio ambiente, comparando com os filtros sintéticos. A capacidade de absorção da luz ultravioleta pelos cromóforos de cada molécula, associada possivelmente a atividade antioxidante, fazem parte dos critérios para a escolha dos novos ativos.

Pesquisas com produtos de origem natural possuem um amplo potencial para proteção contra os raios UV, além do mais os consumidores estão cada vez mais exigentes em relação a estética, e se preocupam em obter o benefício oferecido pelo produto, dessa forma encontram maior segurança em utilizar cosméticos à base de insumos vegetais ${ }^{15,16}$.

A literatura é escassa de estudos com extratos hexânicos visando fotoproteção. Esse estudo, no entanto, demonstra através dos resultados expressos na Tabela 1, que as concentrações de 500 e $1000 \mu \mathrm{g} / \mathrm{mL}$ alcançam fator de fotoproteção (FPS) suficiente, sugerindo-o como uma alternativa natural para o mercado de fitocosméticos.

CONCLUSÃO

Portanto, os resultados dessa pesquisa in vitro mostram-se favoráveis para a utilização do FPS do Extrato Hexânico de Psidium guineense sw. em determinadas concentrações, sendo um estudo pioneiro e inovador para área. No entanto, é importante a realização de mais estudos, para comprovar a possibilidade de ser utilizado como fotoprotetor e esclarecer os metabólitos responsáveis por essa atividade. Além disso, é uma forma de fomentar a economia de uma região.

\section{REFERENCIAS}

1. Sgarbi FC, do Carmo ED, Rosa LEB. Radiação Ultravioleta e carcinogênese. Rev Ciênc Med. 2007;16:245-50.

2. Cabral LDS, Pereira SO, Partata, AK. Filtros solares e fotoprotetores - uma revisão. Infarma. 2013;25(2):107-10.

3. Polonini HC, Raposo NRB, Brandão MAF. Fotoprotetores naturais como instrumento de ação primária na prevenção do câncer de pele. Rev Aps. 2011;14(2):216-23.

4. Martins DBS. Desenvolvimento e testes de estabilidade de protetor labial com vitamina $\mathrm{E}$. [monografia] Brasília: Curso de Farmácia, Universidade de Brasília - UNB; 2015.

5. Viegas Junior C, Bolzani VS, Barreiro, EJ. Os produtos naturais e a química medicinal moderna. Quím Nova. 2006;29(2):326-37.

6. Castilho AR, Murata RM, Pardi V. Produtos Naturais em Odontologia. Rev Saúde. 2007;1:11-5.

7. Violante IMP, Souza IM, Venturini CL, Ramalho AFS, Santos RAN, Ferrari M. Avaliação in vitro da atividade fotoprotetora de extratos vegetais do cerrado de Mato Grosso. Rev bras farmacogn. 2009;19:452-57.

8. Caldeira SD, Hiane PA, Ramos MIL, Ramos 
Filho MM. Caracterização físico-química do araçá (Psidium Guineense sw.) e do tarumã (Vitex Cymosa Bert.) do estado de Mato Grosso Do Sul. B.Ceppa. 2004;22(1):145-54.

9. Rodrigues, CG. Atividade antibacteriana de taninos extraídos de folhas de psidium guineense sw. (myrtaceae)[dissertação]. Montes Claros: Curso de Ciência Biológicas, Universidade Estadual de Montes Claros; 2008

10. Mansur JDS, Breder MN, Mansur MC, Azulay RD. Determinação do fator de proteção solar por espectrofotometria. [Determination of sun protection factor by specrophotometry] An Bras Dermatol. 1986;61:121-24.

11. Sayre RM, Agin PP, Levee GJF. A comparison of in vivo and in vitro testing of sunscreening formulas. Photochem Photobiol. 1979;29:55966.

12. Brasil. Agência nacional de vigilância sanitária. Regulamento técnico sobre protetores solares em cosméticos. Rdc $n^{\circ} 30$, de $1^{\circ}$ de junho de 2012. p. 1-7

13. Guaratini T, Callejon DR, Pires DC, Lopes JNC. Fotoprotetores derivados de produtos naturais: perspectivas de mercado e interações entre o setor produtivo e centros de pesquisa. Quim Nova. 2009;32:717-21.

14. Oliveira Junior RG, Almeida JRGS. Prospecção tecnológica de fotoprotetores derivados de produtos naturais. Geintec. 2012;3:32-40.

15. Minami SK, Brunelli GT, Vallone MS, Moreira MAL, Moraes CAP. Desenvolvimento de loção fotoprotetora à base de extratos vegetais para a pele da mão. InterfacEHS. 2015;10(1):18-27.

16. Nascimento LF, Santos EP, Aguiar AP. Fotoprotetores Orgânicos: Pesquisa, Inovação e a Importância da Síntese Orgânica. Rev Virtual Quim. 2014;6:191-223.

\section{CONFLITO DE INTERESSES}

Os autores declaram não haver conflitos de interesse

\section{AUTOR PARA CORRESPONDÊNCIA}

\author{
Aleson Pereira de Sousa \\ Universidade Federal da Paraíba (UFPB) \\ João Pessoa - PB, Brasil \\ E-mail: aleson_155@hotmail.com
}

Submetido em 19/01/2021

Aceito em 01/07/2021 